\title{
Against a unified treatment of obligatory presupposition trigger effects*
}

\author{
Athulya Aravind \\ MIT
}

\author{
Martin Hackl \\ MIT
}

\begin{abstract}
This paper examines bi-sentential sequences where additive presupposition triggers (e.g. too, again) seem to be obligatory in the second sentence. We present linguistic and experimental evidence against treating these obligatory additivity effects as uniformly following from Maximize Presupposition! (Heim 1991). We propose that the environments giving rise to these effects involve a discourse move that corrects for over-restrictive assumptions about the domain in the immediately preceding move. Crucially, the second move must be compatible with the first. General considerations about how the discourse unfolds, in conjunction with a principle that sentences are interpreted exhaustively by default, make it so that two sentences in such sequences are mutually inconsistent in the absence of the additive.
\end{abstract}

Keywords: additives, maximize presupposition, exhaustivity, experimental pragmatics

\section{Introduction}

Heim's (1991) pragmatic principle Maximize Presupposition (MP) mandates that a speaker choose the presuppositionally strongest statement among a set of contextuallyequivalent alternatives. Though originally proposed to account for the preference for the definite article in sentences like (1), MP has since been recruited to account for similar contrasts involving various other lexical items (Percus 2006; Chemla 2008; Sauerland 2008). A partial list is provided in (2).

(1) The/\#A sun is shining.

(2) a. I washed both/\#all of my hands.

b. Does your dog have a bushy tail/\# bushy tails?

c. Sam knows/\#thinks that Paris is in France.

* We are grateful to Maria Biezma, Kate Davidson, Danny Fox, Irene Heim, Sabine Iatridou, Roni Katzir, Loes Koring, Jon Ander Mendia, Jesse Snedeker and audiences at MIT's LF Reading Group and SALT 27 for helpful comments and discussion.

(C2017 Aravind and Hackl 
In each of the above examples, the preference for the presuppositionally stronger sentence (and the oddity of the weaker one) is derived as follows. The sentencepairs are contextually equivalent, and as such, a cooperative speaker who obeys MP would use the presuppositionally stronger alternative when the presupposition holds. A speaker's choice of the weaker variant therefore invites an inference, an antipresupposition, that the speaker believes that the relevant presupposition is not met in the context of utterance. However, our common knowledge about the uniqueness of the sun, the duality of human hands, etc. ensures that the presuppositions of the sentences above are met in all typical contexts. The perceived oddity of the presuppositionally weaker sentences derives from the fact that the anti-presuppositions triggered by their use (e.g. that the speaker believes there is more than one sun) run counter to our expectations (about the speaker's knowledge ${ }^{1}$ ) about the world.

We also find purported MP-effects involving additive presupposition triggers ("obligatory additivity effects" henceforth) (Amsili \& Beyssade 2009; Chemla 2008; Singh 2011). ${ }^{2}$ Unlike the canonical cases of MP in (1) and (2), competition in (3-5) seems to be between the additive expression and its absence, raising questions about the nature of these effects. Are they in fact MP effects?

a. Dana went to a party. Lee went to a party, too.

b. \#Dana went to a party. Lee went to a party.

a. Dana went swimming yesterday. She went swimming again today.

b. \#Dana went swimming yesterday. She went swimming today.

a. Sam was in New York yesterday. She is still there today.

b. \#Sam was in New York yesterday. She is there today.

In this paper, we explore and develop an analysis of this phenomenon. We begin by presenting linguistic and experimental evidence that motivate a treatment of obligatory additive effects as distinct from MP-effects. Our account builds on previous work that takes these effects to be a rescue strategy for avoiding problematic implicatures (Krifka 1999; Saebø 2004; Bade 2016). We argue that the oddity of the (b)-variants in (3-5) stems from competing demands: ( $i$ ) the need to interpret sentences exhaustively by default, and (ii) the need for mutual consistency between sequential utterances by the same speaker. The main component of the analysis consists of treating the second sentence as a special sort of revision of the first sentence, one that involves a speaker correcting for her over-restrictive initial assumptions

1 For readability's sake, the discussion of anti-presuppositions in this paper may sometimes omit the reference to the speaker's belief states, but none of our arguments hinge on this aspect.

2 Judgments about these sequences vary with intonation. To get the relevant effect, the examples should be read with falling or closure intonation on both sentences. 
Obligatory presupposition trigger effects

about what facts might be relevant to the conversational goals. More specifically, we take these two sentences to be interpreted exhaustively relative to distinct — but related - questions under discussion, differentiated only by the size of the domain that is taken into account in each case. Due to the nature of these questions, the end result is that these types of sequences are well-formed only when the second sentence contextually entails the first. Insertion of additives is one way of meeting this requirement, perhaps one among many.

We begin in $\S 2$ by showing that obligatory additivity effects disappear in various environments where classical MP effects remain. $\$ 3$ presents experimental evidence that classical MP-effects and obligatory additivity effects show different processing signatures. We then turn to the analysis: $\S 4.1$ presents assumptions from previous analyses that our own builds on and discusses shortcomings that motivate our amendments; in section $\$ 4.2$ and $\S 4.3$ we present the formal details of our proposal.

\section{Obligatory additivity effects vs. classical MP effects}

Sentences without too/again are degraded in contexts where those additive particles would have been felicitous. An MP-based account would derive the infelicity of the (b)-sequences in (3)-(5) as follows. Sentences with and without the additives enter into MP-based competition. When the presuppositionally stronger alternative is not used, the listener reasons that it could not have been used, presumably because its presuppositions are not met. In contexts that support the additive presupposition $p$ (i.e. the shared beliefs of speaker and hearer entail $p$ ), using a contextually equivalent form without the additive particle would lead to inconsistency based on MP. This would happen on the assumption that not using the trigger leads the listener, by MP, to conclude that the speaker does not believe that the stronger statement is supported in the context, which is inconsistent with the starting assumption.

When we look beyond the basic cases, however, we find that sometimes obligatory additivity effects surface where MP-effects would not and vice versa. As pointed out in Rouillard \& Schwarz 2017, the set of alternatives relevant for MP is restricted by structural complexity. ${ }^{3}$ To illustrate, consider their examples in (6-7).

(6) a. The guest left. $\rightarrow$ Presupposes: There is exactly 1 guest.

b. A guest left. $\rightarrow$ Anti-presupposes: It's not the case that there is exactly 1 guest.

(7) a. The two guests left. $\rightarrow$ Presupposes: There are exactly 2 guests.

b. The guests left. $\rightarrow \rightarrow$ Anti-presupposes: It's not the case that there are exactly 2 guests.

3 Following Katzir (2007), we can take this to be a general property of alternative-generation. 
The sentence in (6b) triggers the inference that the presupposition of the definite article, namely that there is exactly one guest, is not met in the context of utterance. However, we fail to see a parallel inference when (7b) is used: though the plural definite the guests is presuppositionally weaker than the two guests, its use does not lead to the inference that more than two guests were present.

A generalization that we can form from facts like these is that a sentence $S$ competes with a presuppositionally weaker sentence $S^{\prime}$ only if it is at most as complex at S'. Since the two is structurally more complex than the, it is not a suitable alternative for sentences involving the. Additives, however, are a counter-example to such a generalization: sentences with additives are structurally more complex than their additive-less counterparts, and thus expected not to compete with them under a complexity-sensitive version of MP. The fact that we find obligatory additivity effects nevertheless is puzzling on an MP-based account of them.

Another feature of obligatory additivity effects that sets them apart from classical MP-effects is their disappearance in embedded contexts. As noted by Percus (2006) and Sauerland (2008), MP-effects arise in complex sentences even when the competitors don't vary in presuppositional strength globally. The presuppositions of (8a) and (9a) are locally satisfied and therefore do not differ in presuppositional strength from their counterparts in (8b) and (9b). Yet, the (b) sentences are infelicitous.

a. She only has one daughter and her daughter is very young.

b. \#She only has one daughter and a daughter of hers is very young.

a. If John has exactly two students and he assigned the same exercise to both of his students, then I'm sure he will be happy.

b. \#If John has exactly two students and he assigned the same exercise to all of his students, then I'm sure he will be happy.

One explanation for these facts is that competition for MP takes place "locally", either at the level of the lexical item (Percus 2006), or perhaps sub-sententially, at each local context (Singh 2011). But unlike classical MP effects, the obligatoriness of additives disappears in embedded contexts (Bade 2016). In examples (10) and (11), which are structurally parallel to (8-9), we find no evidence for competition at the local level: the sentences with and without the additive are judged felicitous.

(10) a. Dana went to the party and Lee went to the party, too.

b. Dana went to the party and Lee went to the party.

(11) a. If Dana went to the party and Lee went to the party too, it will be fun.

b. If Dana went to the party and Lee went to the party, it will be fun.

Finally, unlike canonical MP-effects, obligatory additivity effects disappear in list environments. Consider first the pair of lists in (12), involving the presupposition 
Obligatory presupposition trigger effects

trigger both and the otherwise identical sequence involving all. The use of all in (12b) leads to an inference that at least one of John's sisters is polygamous. This can straightforwardly be derived as an anti-presupposition resulting from the failure to use both, since the first two list items ensure that the duality presupposition of both is supported in the context of utterance.

a. John was there... His two sisters were there... The sisters' spouses were both there...

b. John was there... His two sisters were there... The sisters' spouses were all there...

The absence of additives in list-sequences like (13), however, does not lead to inferences of exclusivity, as predicted on an MP account.

(13) Dana went to the party... Lee went to the party... Sue went to the party...

Together, these observations suggest that additives form a different class from triggers like the and both. But this does not rule out the possibility that they simply instantiate a different type of MP-effect. To fully motivate a non-uniform treatment of these two classes of phenomena, it needs to be shown that MP is not involved in the generation of obligatory additivity effects at all. This will be our goal in the following section. As described above, the oddity of presuppositionally weaker sentences is generally thought to come about via the listener's reasoning about contextually-equivalent, but presuppositionally stronger, alternatives that could have been used. If speakers derive obligatory additivity effects based on a corresponding rationale, we might expect parallel processing behaviors in tasks that probe for speakers' evaluation of expressions in competition for conveying the same message.

\section{Experiment}

\subsection{Methods and materials}

In a Binary Decision Task, participants first saw a sequence of two images depicting an event. They then saw competing (written) descriptions of that event and were asked to choose the better one. They were told that one description may be worse than the other because it is false, ungrammatical or simply odd-sounding. Sentence-choice as well as response times were collected as dependent measures. Target sentences involved four presupposition triggers, competing with their non-presuppositional counterparts; there were 4 items per trigger. Two of the triggers, the (vs. $a$ ) and both (vs. all), belonged to the "classical"-MP class and the other two, too (vs. $\emptyset$ ) and again (vs. $\emptyset$ ), were additives. Figure 1 illustrates. 


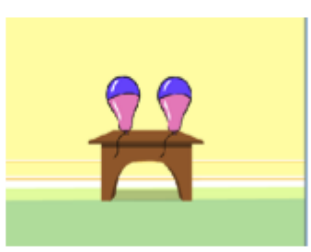

Look! Two balloons!

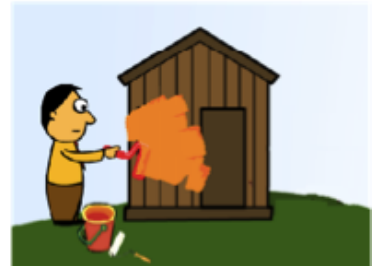

Look! A man is painting a house!

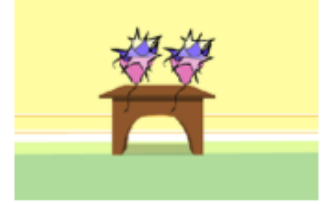

Both of the balloons popped. All of the balloons popped.

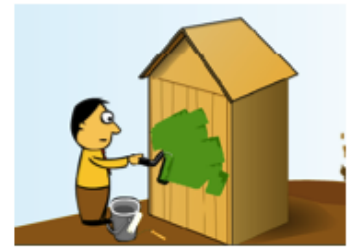

Now the man is painting one, again. Now the man is painting one.

Figure 1 Example critical items

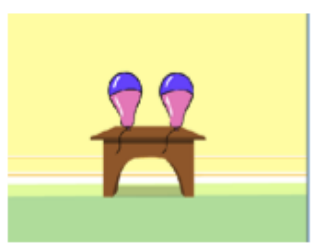

Look! Two balloons!

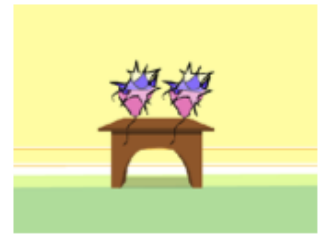

Both of the balloons popped. All of the balloons popped.

Figure 2 Example filler item, length-matched for again

Because of inherent differences in the nature of the lexical items involved, the critical sentences varied in length across triggers. Consequently, for each trigger, we employed length-matched filler items as a baseline (Figure 2). Whereas the critical items involved sentences with and without the presupposition triggers in environments where the presupposition is met, filler items involved similar sentences where one sentence was simply false.

\subsection{Results and discussion}

Results from 80 participants, recruited via Amazon Mechanical Turk, are described below. Results from 1 participant was excluded due to low performance $(<60 \%)$ 
Obligatory presupposition trigger effects

\begin{tabular}{lcccc}
\hline Contrast & $\beta$ & SE & $t$ & $p$ \\
\hline \hline Both-Critical vs. Both-Filler & 419.10 & 109.45 & 3.829 & $<.001$ \\
The-Critical vs. The-Filler & 312.26 & 109.32 & 2.856 & 0.008 \\
Too-Critical vs. Too-Filler & -122.78 & 109.80 & -1.118 & 0.27 \\
Again-Critical vs. Again-Filler & -13.54 & 109.80 & -0.124 & 0.90 \\
\hline
\end{tabular}

Table 1 Summary of planned comparisons

on filler items. In addition, we trimmed response times that were 2.5 SDs above and below the mean of each participant. Overall, these exclusions affected $4.58 \%$ of the data. Accuracy rates on all conditions were above $90 \%$, with no significant differences across type (critical/filler) or trigger. The dependent measure we focus on here will be the time it took participants to choose between the two sentences. The sentences varied in length across triggers (e.g. sentences in the both condition were between 5-6 words, compared to 8-10 words in the too condition), and so, a direct comparison of decision times is not meaningful. We therefore compare the relative differences in decision times between critical and length-matched filler items for each condition. Recall that filler items required participants to choose between TRUE vS. FALSE descriptions of the situation pictured. We reasoned that decision times for such cases could serve as a fair estimate of the minimum amount of time it takes to compare two sentences of a given length in this task. Deviation from this baseline could, in turn, serve as a measure of processing difficulty.

Figure 3 displays mean decision times on critical and filler items for each trigger. We see a marked difference between participants' behavior on the determiner triggers compared to the additives. With too and again, decision times on critical and filler items are comparable. However, participants took comparatively much longer to make a decision on critical items with both and the relative to the fillers. A $2 \times 2$ linear mixed effects model with Class (classical MP vs. obligatory additive) and Type (critical vs. filler) as interacting factors confirmed these trends. The results revealed a significant interaction of Class and Type, with participants taking longer on critical items only on the classical-MP items $(\beta=522.48, \mathrm{SE}=205.35, \mathrm{t}=2.5$, $p=.02$ ). Planned comparisons for differences between critical and filler items by trigger, summarized in Table 1, further confirmed that the two classes are treated differently. Decision times between critical and filler items varied significantly only for both and the.

These results reveal that speakers draw a distinction between classical MP effects and obligatory additivity effects in processing. The longer decision times on critical items relative to fillers in the determiner conditions are perhaps unsurprising if 


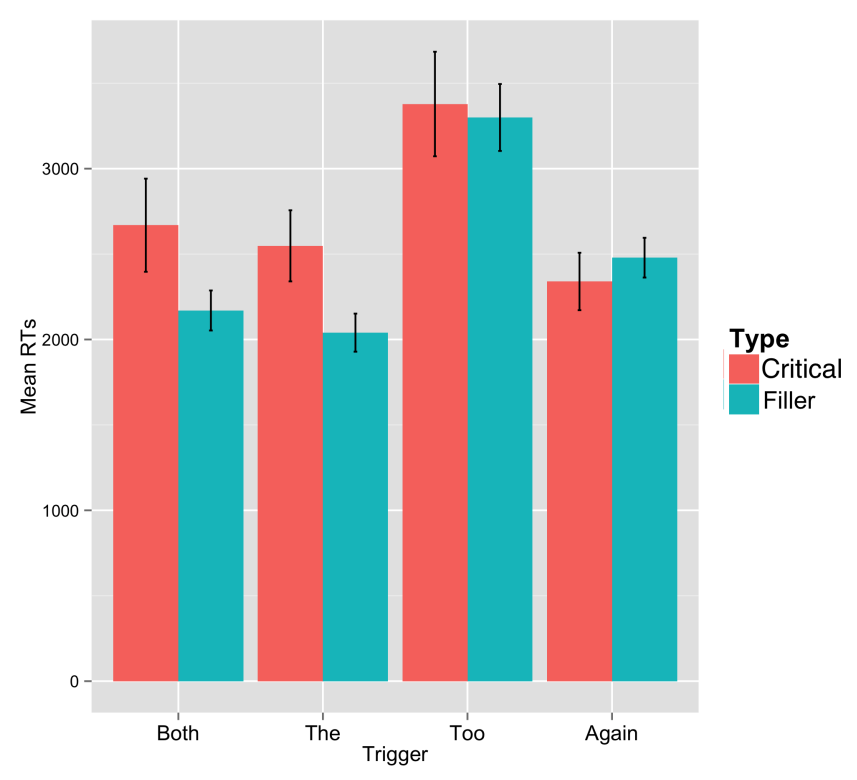

Figure 3 Mean decision times: critical vs. filler items

we take the competing sentences to be contextually equivalent: only by the added application of a principle like MP can speakers choose between them. If choosing between sentences with and without additives proceeded in a parallel fashion, we would again expect to find a difference in decision times between critical items and the respective control items. We fail to find such a difference. Our findings therefore speak against a simple minded subsumption of obligatory additivity effects under the umbrella of MP.

\section{A non-MP account of obligatory additivity effects}

\subsection{Exhaustivity and additives}

The linguistic and experimental facts seen so far invite entertaining an approach to obligatory additivity effects that do not appeal to MP. There have been a few such proposals (e.g. Krifka 1999; Saebø 2004; Bade 2016). A common thread among such approaches is the intuition that too is necessary in sequences like those in (14) because its absence leads to problematic implicatures.

(14) a. Dana went to a party. Lee went to a party, too.

b. \#Dana went to a party. Lee went to a party.

For reasons of space, we focus here on a recent proposal by Bade (2016). 
Obligatory presupposition trigger effects

The sequence in (14b) is diagnosed to be ill-formed because it comprises, in a manner to be explicated, of two mutually inconsistent propositions. In the second sentence of the sequence, the subject, Lee, is taken to bear focus, as it is the only constituent that is new. Focus is argued to require the presence of a focus-sensitive operator that can associate with it. In the absence of an overt one, comprehenders assume the presence of a covert focus-sensitive operator, EXH (Fox 2007; Chierchia, Fox \& Spector 2012), which conveys exclusivity as part of its meaning. EXH is taken to be blind to context (Magri 2009), so its insertion cannot be blocked by the contents of a previous utterance. If focus on Lee in (14b) leads the listener to parse the sentence with a context-blind ExH, a contradiction ensues: the speaker would be understood to say that Dana went to a party, and in the next breath, that only Lee did. The problem does not arise with additives because they are focus-sensitive operators themselves and so can associate with the F-marked constituent. In their presence, therefore, EXH is not necessary and thus not inserted.

This proposal yields a number of welcome results. The fact that, unlike canonical MP effects, obligatory additivity effects do not arise in certain embedded contexts can be explained. Though (15) conveys the same information as the sequences in (14), EXH has a different scope site available in (15): it can be inserted above the entire conjunction, resulting in the unproblematic (and potentially welcome) inference that Dana and Lee and no one else went to a party.

Dana went to the party and Lee went to the party, $\{$ too/Ø $\}$.

Given the independently noted fact that list intonation - i.e. a final rise on (non-final) list items - correlates with non-exhaustivity (e.g. Bolinger 1982, Zimmerman 2000, Gunlogson 2008), the absence of obligatory additivity effects in lists is expected. For reasons that remain poorly understood, EXH cannot attach above individual list items and the problematic exclusivity inference does not arise in the first place.

The account also helps us make better sense of our experimental results. A question that arises is: why did MP-items incur longer decision times than fillers, whereas with additives, decision times were as fast as with the fillers? Bade's answer might be as follows. MP-items are associated with a processing delay, as they involve a comparison of otherwise equivalent alternatives. However, because sequences without additives are contradictory, they are necessarily false. In this regard they are similar to fillers: in both cases, the choice can be resolved through a simple process of elimination of the false sentence.

The main setback of the analysis is that Bade's system predicts too few exhaustivity inferences. For instance, the first sentence in the sequence is assumed to be non-exhaustive. This is crucial, since continuations with or without too would otherwise yield inconsistency. But sentences like (16) suggest that the first sentence also receives an exhaustive interpretation. 
\#Dana's food is warm. Lee's food is hot, too.

Before getting into the details of (16), a word about too is in order. A characteristic property of additive particles like too is that they have an anaphoric component, and require a parallel antecedent (Lakoff 1971; Heim 1992; Kripke 2009). In the absence of a suitable antecedent, one can be accommodated if it is inferable from something else in the discourse. This is why we conclude in (17) that being called a Republican is tantamount to an insult to Dana (and perhaps the speaker): though calling someone a Republican need not ordinarily be interpreted as an insult, the parallel antecedent requirement of too in the second sentence necessitates this bridging inference.

(17) John called Dana a Republican. Lee insulted her, too.

Why is something analogous impossible in (16)? After all, a non-exhaustive interpretation of the first sentence is consistent with Dana's food being hot, which could then license accommodation of a parallel antecedent for the second sentence. The issue, at an intuitive level, is that the first sentence is taken to convey that Dana's food is only warm - i.e. it is interpreted exhaustively - and thus cannot license accommodation of a parallel antecedent of the form: $x$ 's food is hot.

Perhaps more problematically, we find exhaustivity effects in the second sentence in the presence of too. For instance, the second sentence of B's response in (18) seems to suggest that besides Bill, Sue is the only person who got a 100 on the exam.

(18) A: Give me the names of everyone who got a 100 on the exam.

B: Bill got a 100. Sue did, too.

$\rightarrow$ Sue and Bill got a 100, and no one else did.

This is unexpected in Bade's proposal, where EXH and too are in complementary distribution.

Finally, on this account, any focus-sensitive operator may serve the role of circumventing exhaustivity implications, so long as the resulting meaning is consistent: focus operators use up all F's in their scope, leaving nothing for EXH to associate with and thus precluding its insertion. But no insight is gained into why these are understood to be obligatory additivity effects, in other words, something we take to be key for a full understanding of the phenomenon.

Our goal in what follows, therefore, is to offer an amendment of Bade's account, taking the above observations as our guide. We begin by considering when speakers might produce sequences with additives, as in (19a), as opposed to the more to-thepoint conjunctive statement in (19b).
a. [s1 Dana went to a party.] [s2 Lee went to a party.]
b. Dana and Lee went to a party. 
Obligatory presupposition trigger effects

We propose that $\mathrm{S} 2$ in (19a) is best understood as a revision of the first, involving a readjustment of the speaker's initial assumptions about the domain. ${ }^{4}$ In brief, upon uttering S1, the speaker takes herself as providing a complete (i.e. exhaustive) answer to a question of the form "Who went to the party?". Like quantifiers, the domains of $w h$-phrases are implicitly restricted, and the speaker initially assumes a restriction that does not include Lee. However, assumptions about domains may change between two utterances. The speaker may realize that her initial assumptions were too restrictive, that there may be other individuals whose attendance at a party is relevant. S2 remedies this situation by offering additional information that supplements S1. Crucially, S2 is also interpreted exhaustively, but relative to a question that differs from the first only in that a broader domain is now being considered. A consequence of this is that unless S2 contextually entails S1, a contradiction will ensue.

\subsection{The ingredients}

\subsubsection{The QUD model of discourse}

The first necessary ingredient is a way of modeling the discourse. To start, we adopt Stalnaker's (1978) notions of the Common Ground and Context Set, representing the shared information accessible to the participants in the conversation at any given time. When an assertion is made (and accepted), that proposition is intersected with the context set, resulting in an updated context set that is smaller (i.e. has fewer worlds) than before.

(20) Common Ground $(\mathrm{CG})=\{\mathrm{p}$ : for each speech act participant $\mathrm{x}, \mathrm{x}$ believes $\mathrm{p}\}$

$$
\text { Context Set }(\mathrm{C})=\cap \mathrm{CG}
$$

We also assume the question-based model of discourse in Roberts 1996/2012. Speech act participants establish conversational goals by raising questions. The most immediate issue is that the interlocutors are attempting to resolve at time $t$ is the Question Under Discussion (QUD) at $t$. Speakers tailor their assertions relative to the QUD. If one is not explicit, they construct one on the fly (accommodation), taking discourse properties, goals, etc. into account.

Question-raising, explicit or accommodated, is subject to certain constraints. First, a condition on triviality, as in (22), mandates that questions should not be raised whose answers are already known (e.g. Büring 2003).

(22) Don't ask trivial questions!

$$
\text { A question } \mathrm{Q} \text { is trivial in } \mathrm{C} \text { if } \forall \mathrm{p} \in \llbracket \mathrm{Q} \rrbracket \cdot \mathrm{p} \cap \mathrm{C}=\mathrm{C} \vee \mathrm{p} \cap \mathrm{C}=\emptyset
$$

4 It is not a correction, however: what is being amended cannot be the content of S1, since we understand $\mathrm{S} 2$ as being compatible with $\mathrm{S} 1$. 
The space of possible QUDs is further constrained by Question-Answer Congruence (QAC), which following Rooth (1992), may be stated as requiring that a sentence is a good answer to a question only if the question meaning is a subset of the focus alternatives of that sentence (23).

\section{(23) Question Answer Congruence}

If $\mathrm{S}$ is an answer to a question $\mathrm{Q}$, then $\llbracket \mathrm{Q} \rrbracket \subseteq \llbracket \mathrm{S} \rrbracket^{f}$

One result of a constraint like the QAC is that focus marking in assertions provides an important cue as to what question can be accommodated.

\subsubsection{Exhaustification}

A second key ingredient of our analysis is exhaustivity. Every sentence is mandatorily interpreted exhaustively relative to the QUD, unless explicitly marked as being non-exhaustive/incomplete (Scharten 1997; Magri 2009; Meyer 2016). Like Bade (2016), we adopt a grammatical approach to exhaustivity implicatures (Fox 2007; Magri 2009; Chierchia et al. 2012). The ExH-operator, defined in (24), is taken to be present at LF for every sentence that receives an exhaustive interpretation. The operator takes a set of propositional alternatives, provided by the QUD, and a proposition $p$ and asserts that $p$ holds and for any non-weaker proposition $q$ in the alternative set, that $q$ is false.

$$
\llbracket \operatorname{Exh} \rrbracket(\mathrm{QUD})(\mathrm{p})=\lambda \mathrm{w} \cdot \mathrm{p}(\mathrm{w}) \wedge \forall \mathrm{q} \in \mathrm{QUD}[\mathrm{p} \not \mathrm{q} \rightarrow \mathrm{q}(\mathrm{w})=0]
$$

\subsubsection{The meaning of additives}

We focus here on too, with the expectation that the analysis extends with minimal modification to other additives like again. Most analyses of too agree that it is both focus-sensitive and anaphoric (Kripke 2009; Heim 1992; van der Sandt \& Huitink 2003). We will take too to require a propositional antecedent and to presuppose that this proposition is true. We saw in 4.1 that sentences with too convey exhaustivity of a certain kind: specifically, it is conveyed that nothing but the prejacent and the antecedent propositions is true. What this means, given our assumptions about exhaustivity, is that the antecedent needs to be visible to EXH. We take this to be evidence that the antecedent is not only presupposed but also part of the asserted content (see also van der Sandt \& Huitink 2003; Ahn 2015).

Our formal analysis is couched within Rooth's (1992) Alternative Semantics, wherein each expression $\alpha$ has two different semantic values: its ordinary semantic value, $\llbracket \alpha \rrbracket^{o}$, and its focus semantic value $\llbracket \alpha \rrbracket^{f}$, the latter consisting of a set of alternatives to $\alpha$. Too takes two arguments, the host proposition, its prejacent, and a 
Obligatory presupposition trigger effects

propositional antecedent (represented with an index on $t o o$, as in $t o o_{i}$ ) and asserts the conjunction of the two. It is defined, however, only if the value assigned to the index by the interpretation function is a true proposition in the set of alternatives, which is distinct from the prejacent.

a. 【too $i p \rrbracket^{g, w}$ is defined iff

i. $\mathrm{g}(\mathrm{i})$ is true at $\mathrm{w}$

ii. $\exists q \neq p \in \llbracket p \rrbracket^{f}$ such that $q=\mathrm{g}(\mathrm{i})$

b. If defined, then, $\llbracket \operatorname{too}_{i} p \rrbracket^{g, w}=\llbracket p \wedge q \rrbracket^{g, w}$

\subsection{Putting the pieces together}

In what follows, the analytical pieces laid out above are put together to account for the contrast in (26).

a. \#[Dana went to a party. $]_{\mathrm{S} 1}[\text { Lee went to a party. }]_{\mathrm{S} 2}$

b. $\sqrt{ }[\text { Dana went to a party. }]_{\mathrm{S} 1}$ [Lee went to a party, too. $]_{\mathrm{S} 2}$

Both sentences in these bi-sentential sequences are, by default, interpreted exhaustively relative to some QUD. Since exhaustively answered questions are resolved, two separate questions are being addressed and must be accommodated. What questions are these? On their most natural reading, both sentences are pronounced with F-marking on the subjects. Thus, the form of the focus alternatives for both sentences will be as in (27).

$$
\left\{\mathrm{p}: \exists \mathrm{x} \in \mathrm{D}_{e} \& \mathrm{p}=[\lambda \mathrm{w} . \mathrm{x} \text { went to a party in } \mathrm{w}]\right\}
$$

Question-Answer Congruence dictates that the meaning of the accommodated question for these sentences be a subset of the set of their focus alternatives. Thus:

$$
\llbracket \mathrm{Q} \rrbracket \subseteq\left\{\mathrm{p}: \exists \mathrm{x} \in \mathrm{D}_{e} \& \mathrm{p}=[\lambda \mathrm{w} . \mathrm{x} \text { went to a party in } \mathrm{w}]\right\}
$$

Of course, in practice, the domain $\mathrm{D}_{e}$ is restricted in the context. For instance, given that the listener can reasonably assume that the individuals being discussed are human, the most natural QUDs are who-questions. Moreover, the speaker does not intend her utterances to convey - nor does the listener interpret the utterance as conveying — an exhaustive listing of every party-goer in the world. Thus question accommodation takes place with the understanding that the intended space of answers is restricted to some relevant set of individuals.

Returning to the sequences in question, suppose that for $\mathrm{S} 1$, the accommodated question is in (29), where D1 represents the contextually-relevant subset of $\mathrm{D}_{e}$ the speaker is assumed to have in mind. 


$$
\mathrm{Q} 1=\mathrm{Who}_{D 1} \text { went to a party? }
$$

$\mathrm{S} 1$ is parsed with EXH, leading to the implication that Dana is the only person in D1 who went to a party. We come now to S2. The information structure of S2 is identical to $\mathrm{S} 1$ and so, the question it is answering should in principle be identical to Q1. However, accommodating Q1 again would violate the triviality condition on question-asking (22): S1 already resolved the issue of who in D1 went to a party. Yet the information-structural constraints require that a question of the form, Who went to the party? is accommodated.

One way out of this predicament is to accommodate a distinct but related question which differs from Q1 only in the size of the domain. This domain broadening may be cued by reasoning about what is expected from a cooperative interaction. A cooperative speaker is expected to assert some proposition $p$ in $\mathrm{C}$, the current context set, only if the truth of $p$ is not settled in C. On the basis of this assumption and the speaker's utterance of S2, the listener can reason that the issue of whether or not Lee had gone to a party was not settled in C. But this can only be so if the previously assumed domain did not in fact include Lee. The listener will infer (and the speaker assumes that the listener will infer and so on) that $\mathbf{S} 2$ is therefore an addendum to $S 1$, intended to be interpreted relative to broader assumptions about the domain. Thus, the QUD accommodated for S2 will be identical to the first, except for the fact that the domain is broadened to include at least one more individual (in this case Lee), e.g. (30).

$$
\mathrm{Q} 2=\mathrm{Who}_{D 2} \text { went to a party? where } \mathrm{D} 1 \subset \mathrm{D} 2
$$

Again, given our assumptions about exhaustification, S2 is interpreted exhaustively relative to Q2. This is where the presence vs. absence of the additive makes a difference. An exhaustive interpretation of S2 in the additive-less (26a) would lead to the implication that in the now broadened domain, D2, Lee is the only individual who went to a party. However, update of the context with this proposition would result in $\emptyset$, as every world in $C$ is one in which at least one other individual, namely Dana, has gone to a party. In fact, given what we have said about the relationship between the two accommodated QUDs in (30), the only circumstance where an exhaustive interpretation of $\mathrm{S} 2$ would not result in a contradiction in $\mathrm{C}$ is when $\mathrm{S} 2$ contextually entails S1.

Our lexical entry for too in (25) ensures that this requirement is met when S2 contains the additive. Too requires a parallel propositional antecedent, i.e. the antecedent must be in the set of focus-alternatives to $L_{e} e_{F}$ went to a party. The only suitable antecedent in the discourse is the preceding sentence, Dana went to a party. Thus:

$[\text { Lee }]_{\mathrm{F}}$ went to a party, too $_{i}$. 
Obligatory presupposition trigger effects

a. Presupposes: Dana went to a party

b. Asserts: Dana went to a party $\wedge$ Lee went to a party

This sentence may be interpreted exhaustively without resulting in inconsistency: EXH may be inserted above too, which would then convey the intuitively correct implication that no one but Lee and Dana went to a party.

To sum up, we argued that the environments where we find obligatory additivity effects involve a sequence of sentences where the interpretation of each subsequent utterance involves a shift in assumptions about the domain. The first sentence is intended as exhaustively answering the QUD under certain implicit assumptions about what is relevant, and the second involves a revision of these assumptions for a consideration of a wider set of potentially relevant facts. In additive-less sequences like (26a), the problem arises because of independent discourse requirements to (i) interpret each of the two sentences exhaustively and (ii) maintain consistency between the two sentences. Additives ensure that the conditions in both ( $i$ ) and (ii) are satisfied, as the exhaustive interpretation of the second sentence with the additive entails the information conveyed by the first.

\section{Conclusions and further issues}

In this paper, we argued that obligatory additive effects are not within the purview of Maximize Presupposition!. Additives do not always show the same linguistic behavior as canonical expressions giving rise to MP-effects; neither do they show the same processing signatures. We proposed an analysis where these effects result from of default exhaustive interpretations of sentences relative to the current QUD and limits on what QUDs may be accommodated. Our analysis is an improvement upon previous exhaustivity-based accounts of these effects, e.g. Bade 2016). It allows us to maintain the desirable results of Bade 2016, while offering a better understanding of why additives are special in their ability to circumvent the problematic inferences.

The account makes certain welcome predictions. Unlike in classical MP cases, the obligatoriness of additives on our account has little to do with their presuppositionality. They are inserted to ensure consistency. If this is right, we expect that non-presuppositional continuations to be able to serve the same function as too, so long as the result is consistent. As shown in (32), this seems to be the case.

Dana went to a party.

a. (In fact,) she and her partner went.

b. (In fact,) her whole family went.

What happens when shifting of the domain is not licensed, perhaps because assumptions about the domain were made explicit? In such circumstances, not even too 
should be able to rescue the structure. As illustrated by (33), this expectation is borne out. $^{5}$

Of all the people who may have attended your party, I only care about Dana and Lee. Which of those two came to your party?

\#Dana did. Lee did, too.

Notice, however, that the revision mechanisms claimed to be at work in the sequences of interest do not seem to be available when the first sentence contains only. Only is generally taken to be the overt counterpart to EXH and so, all else being equal, we should find that the second sentence in (34) is interpreted relative to a broader domain and the entire sequence felicitous.

\# Only Dana went to a party. Lee went to a party, too.

The connection between EXH and only, however intuitive, is not well-understood. In fact, there is good evidence that the two are not fully parallel. For instance, in addition to asserting exclusivity, only is often taken to encode a scalar component (Krifka 1993; Beaver 2004; Klinedinst 2005; Coppock \& Beaver 2011). One possibility is that these differences in presupposition could result in differences in whether a shift in contextual assumptions can be made tacitly and harmoniously. The mixedparallelism between EXH and only we observe in this domain opens up interesting avenues for further research, which we leave for future work.

\section{References}

Ahn, Dorothy. 2015. The semantics of additive either. In Eva Csipak \& Hedde Zeijlstra (eds.), Sinn und Bedeutung 19, 20-35.

Amsili, Pascal \& Claire Beyssade. 2009. Obligatory presuppositions in discourse. In P. Kuehnlein, A. Benz \& C. Sidner (eds.), Constraints in discourse 2: Pragmatics and Beyond, 105-124. Amsterdam: Benjamins.

5 There is a possible reading of (33) as a self-correction. The "corrective" nature of this reading can be made explicit by the fact that it is can be prefaced with "no". This is a different case from the ones we are interested in, where the second sentence would be taken as fully compatible with the first.

(i) Of all the people who may have attended your party, I only care about Dana and Lee. Which of those two came to your party?

Dana did. No, wait... Lee did, too. 
Obligatory presupposition trigger effects

Bade, Nadine. 2016. Obligatory presupposition triggers in discourse - empirical foundations of the theories maximize presupposition and obligatory implicatures. Tübingen: Universität Tübingen $\mathrm{PhD}$ dissertation.

Beaver, David. 2004. Five 'only' pieces. Theoretical Linguistics 30, 45-64. doi:10.1515/thli.2004.006.

Bolinger, Dwight. 1982. Intonation and its parts. Language 58(3), 505-533. doi: $10.2307 / 413847$.

Büring, Daniel. 2003. On d-trees, beans and b-accents. Linguistics and Philosophy 26(5), 511-545.

Chemla, Emmanuel. 2008. An epistemic step for antipresuppositions. Journal of Semantics 25(2), 141-173. doi:10.1093/jos/ffm017.

Chierchia, Gennaro, Danny Fox \& Benjamin Spector. 2012. Scalar implicatures as a grammatical phenomenon. In Klaus von Heusinger, Claudia Maienborn \& Paul Portner (eds.), Semantics: An International Handbook of Natural Language Meaning 3, 2297-2331. Mouton de Gruyter.

Coppock, Elizabeth \& David Beaver. 2011. Sole sisters. In Semantics and Linguistic Theory (SALT) 21, 197-217.

Fox, Danny. 2007. Free choice and the theory of scalar implicatures. In Uli Sauerland \& Penka Stateva (eds.), Presupposition and Implicature in Compositional Semantics, 71-120. Palgrave Macmillan.

Gunlogson, Christine. 2008. A question of commitment. Belgian Journal of Linguistics 21(1), 101-136. doi:10.1075/bj1.22.06gun.

Heim, Irene. 1991. Artikel und definitheit. In Semantik: Ein internationales Handbuch der zeitgenossischen Forschung, 487-535. Berlin: Mouton de Gruyter.

Heim, Irene. 1992. Presupposition projection and the semantics of attitude verbs. Journal of Semantics 9, 183-221. doi:10.1093/jos/9.3.183.

Katzir, Roni. 2007. Structurally-defined alternatives. Linguistics and Philosophy 30, 669-690. doi:10.1007/s10988-008-9029-y.

Klinedinst, Nathan. 2005. Bargains, scales and only. Paper presented at NELS 36.

Krifka, Manfred. 1993. Focus and presupposition in dynamic interpretation. Journal of Semantics 10, 269-300. doi:10.1093/jos/10.4.269.

Krifka, Manfred. 1999. Additive particles under stress. In Devon Strolovitch \& Aaron Lawson (eds.), Semantics and Linguistic Theory (SALT) 8, 111-128. Cornell University, Ithaca, NY: CLC Publications.

Kripke, Saul. 2009. Presupposition and anaphora: Remarks on the formulation of the projection principle. Linguistic Inquiry 40(3), 367-386. doi:10.1162/ling.2009.40.3.367.

Lakoff, George. 1971. Presupposition and relative well-formedness. Semantics: An Interdisciplinary Reader in Philosophy, Linguistics and Psychology 329-340.

Magri, Giorgio. 2009. A theory of individual-level predicates based on blind 
mandatory scalar implicatures. Natural Language Semantics 17(3), 245-297. doi:10.1007/s11050-009-9042-x.

Meyer, Marie-Christine. 2016. Grice and grammar: How cooperative are weak sentences? Paper presented at MIT Workshop on Exhaustivity.

Percus, Orin. 2006. Antipresuppositions. In U. Ueyama (ed.), Theoretical and Empirical Studies of Reference and Anaphora: Toward the Establishment of Generative Grammar as Empirical Science., Japan Society for the Promotion of Science.

Roberts, Craige. 1996/2012. Information structure in discourse: Towards an integrated formal theory of pragmatics. Semantics and Pragmatics 5. doi:10.3765/sp.5.6.

Rooth, Mats. 1992. A theory of focus interpretation. Natural Language Semantics 1(1), 117-121. doi:10.1007/bf02342617.

Rouillard, Vincent \& Bernhard Schwarz. 2017. Epistemic narrowing for maximize presupposition. In Andrew Lamont \& Katie Tetzloff (eds.), North East Linguistic Society (NELS) 47, 1-14.

Saebø, Kjell Johan. 2004. Conversational contrast and conventional parallel: Topic implicatures and additive presuppositions. Journal of Semantics 21, 199-217. doi:10.1093/jos/21.2.199.

van der Sandt, Rob \& Janneke Huitink. 2003. Again. In Amsterdam Colloquium 14, $181-186$.

Sauerland, Uli. 2008. On the semantic markedness of Phi-features. In Daniel Harbour, David Adger \& Susana Béjar (eds.), Phi Theory, 57-82. Oxford: Oxford University Press.

Scharten, Rosemarijn. 1997. Exhaustive interpretation: A discourse-semantic account. Nijmegen: Katholieke Universiteit Nijmegen PhD dissertation.

Singh, Raj. 2011. Maximize presupposition! and local contexts. Natural Language Semantics 19(2), 149-168. doi:10.1007/s11050-010-9066-2.

Stalnaker, Robert C. 1978. Assertion. Syntax and Semantics 9, 315-332.

Zimmerman, Thomas Ede. 2000. Free choice disjunction and epistemic possibility. Natural Language Semantics 8(4), 255-290.

Athulya Aravind

Linguistics and Philosophy

77 Massachusetts Ave

Massachusetts Institute of Technology

Cambridge, MA 02139

aaravind@mit.edu
Martin Hackl

Linguistics and Philosophy

77 Massachusetts Ave

Massachusetts Institute of Technology

Cambridge, MA 02139

hackl@mit.edu 